\title{
Raíces griegas: tan lejanas y tan cercanas..."
}

\author{
Ana María Gispert-Sauch Colis
}

\section{$\&$}

\section{Introducción}

TSidbro de Sevilla en su dora maestra Etimologías, supo unir el "origer", ط sea, de dónde viene un vocablo y la "etimología", que sería el "por qué" se aplica este vocablo a una realidad concreta. Hizo, pues, una distinción entre etimologías ex causa (según lo que es) y etimologías ex origine (según de dónde viene) . Y, como de lo que se trataba era de captar el valor esencial de una palabra, dice Isidoro, "cuando se ha visto de dónde viene un nombre, se comprende más rápidamente su valor, porque el estudio de las realidades es més fácil una vez conocida la etimología" (Etimologías, I, 19, 2) .

Siguiendo en parte esta orientación, presentamos algunas raíces de verbos griegos, lejanos en referencia al tiempo de su origen, pero presentes en nuestro tiempo a través de sus derivaciones. Y, sobre todo persistentes, porque nos transmiten la esencia de significado, la densidad semántica, a la que he aludido en varias ocasiones ${ }^{1}$.

De esta forma, el hoy de muchas de nuestras palabras está impregnado de este pasado clásico que nos invita a recuperar permanentemente su esencia. No en vano y refiriéndonos a Sócrates, podríamos decir que la etimología tiene una función "mayeutica", la de sacar a la luz el núcleo fecundo de las palabras. Veamos algunas de dichas raíces.

\section{Raíces griegas generadoras de palabras castellamas}

- El verbo $\boldsymbol{\gamma} \boldsymbol{\gamma} \boldsymbol{\omega} \boldsymbol{\sigma} \boldsymbol{\omega} \boldsymbol{\omega}$ (= conocer) tiene una raíz $\boldsymbol{W}$ (presente en diversas lenguas indoeuropeas) que contiene una gran densidad 
semántica. Está, de alguna manera, emparentada con la raíz del verbo griego híl $\mu o$ (nacer), lo cual expresa una sugerente relación conceptual entre conocer y nacer. Este parentesco se manifiesta en algunas de las lenguas románicas, como la francesa (naître y comaître) o la catalana (neixer "nacer" y coneixer "bonocer").

De esta raíz surgen una serie de palabras usadas principalmente en el campo de la filosofía:

gnosis, con su desinencia -sis, como proceso de conocimiento.

gnosticismo, con su desinencia -ismo, como doctrina que pretendía conocer instintivamente la naturaleza del universo y el destino del hombre.

agnóstico, con el prefijo negativo a-, término acuñado en el siglo XIX para designar a las personas que niegan tanto el ateísmo como el teísmo, pues consideran que no es posible una respuesta a la duda de la existencia de algún ser superior o Dios.

diagnóstico, con el prefijo que significa dia-, significa el conjunto de signos que permiten conocer las enfermedades.

pronóstico, con su prefijo pro-, equivale al conocimiento previo a lo que va a oarrir.

- El verbo $\boldsymbol{\gamma}$ wo $\boldsymbol{\mu} \boldsymbol{0}$, nacer (con sus raíces múltiples $\boldsymbol{W}$-, $\boldsymbol{\gamma} \boldsymbol{\varepsilon} \boldsymbol{V}$-, rov- que implican el sentido de engendrar), produce numerosos términos:

genio, como la persona misma, y a la vez nombre de la deidad que, según los antiguos, velaba por la suerte de cada uno.

generación, genealogía, genealógico, génesis, genética, todas ellas relacionadas con el origen biológico.

genes, genoma, vocablos científicos modernos, empleados para significar el factor hereditario en las células

genitivo, usado en latín tardío ("genitivus") para significar al engendrador (caso genitivo) de las distintas formas del sustantivo.

progenitor, primogénito, congénito, primigenio, unigénito, términos tomados del latín, pero derivados de la misma raíz griega. 
genitales, órganos que sirven para engendrar.

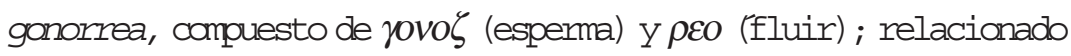
con el origen de la vida.

eugenesia, con el prefijo eu, significa etimológicamente "buen nacimiento" y es aplicado a las leyes de la biología sobre el mejoramiento de las especies.

indígena, vocablo de procedencia latina, pero de origen griego, está formado por inde (de allí) y genus (origen) y significa "el nacidb allí". Curiosamente, la palabra "indio" está formada sobre el mismo adverbio y significa "el de allí". Ias diferencias valorativas entre ambos términos son de carácter cultural, no idiomáticas.

- El verbo lotopew, cuyo significado es saber, conocer, informarse de, explorar (un país), ha originado un término griego, rotopio, que significa búsqueda, averiguación, informe, noticia, resultado de la investigación. A su vez, existe emparentada con éstas el término ı́ruop (conocedor, árbitro) que contiene en su interior el verbo or8 $\alpha$ (saber). Ia "historia" le debe gran parte de su sentido actual a ese arcano significado.

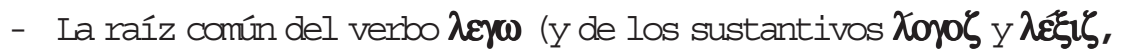
que significan "decir", "palabra", "acción de hablar", respectivamente) pasó al latín como lego, lectum, y encierran también el significado de reunir, juntar, contar, como podemos apreciar en palabras castel lanas, tales como lectura, colecta. Por otra parte, está presente como pseudosufijo con el significado de "estudio", "tratado", en términos tales como antropología, arqueología, cronología, etnología, mitología, meteorología, astrología, psicología, zoología, urología, teología, etc. A la vez, ha dadb origen a otro tipo de palabras como: dialéctica (palabra a través de...) , neologismo usado en ciencias sociales como método filosófico o del conocimiento, (hablar a través de oposiciones, discusión), equivalente etimológicamente a "diálogo" (= palabra o conversación entre dos o más) de la lengua popular. 
- Se encuentra también esta raíz en prolegómenos, con el sufijo pasivo

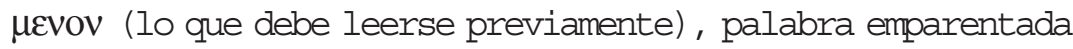
semánticamente con "prólogo" (palabra previa), la cual, a su vez, remite a su antónima "epílogo" (palabra posterior, conclusiva de unescrito) .

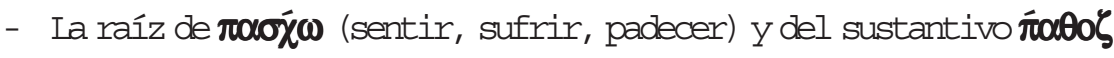
(sufrimiento) aparece en nuestra lengua en palabras como patético, patología, psicópata, como pseudosufijo (segundo término de palabras compuestas) en cardiopatía, homeopatía, osteopatía, psicopatía, telepatía y otras, o como primer miembro de palabras compuestas como: patología, patografía. Es importante señalar la acepción de simpatía (sentir con), vocablo etimológicamente idéntico al término latino compasión (sentir con); de ambas palabras usadas en el lenguaje de la vida cotidiana, aunque emanadas del mismo pozo, la procedente del griego (simpatía) posee una carga o matiz positivo, mientras que su par latino (compasión) entraña una carga negativa, pues significa padecimiento ante la situación penosa de otra persona.

- Una raíz también compleja por sus diversos significados es la que reside en la palabra teoría. Oecopí es el estudio, la contemplación de la verdad, e implica más que un simple constatar o contemplar, pues hay una participación al permitir que se dé la verdad, o sea, un develamiento (Heidegger). Teoría es tener a la vista, en frente, lo que está en cuestión. No se trata de la oposición praxis-teoría (Aristóteles dirá que la teoría es la más alta praxis), pues la teoría implica ya un mirar comprometido, y es un privilegio de la mirada y de la luz en la metafísica (cf. Platón y Aristóteles) . Con esta misma raíz encontramos las palabras:

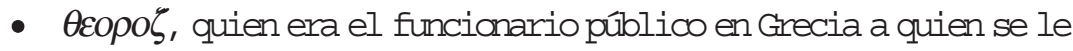
encomendaba asistir a los juegos "para ver", sin intervenir, a fin de que el juego transcurriera de una manera conforme con las reglas predeterminadas. No era un ver por ver, sino ver para constatar, inspeccionar, "vigilar". Este $\theta \varepsilon o \rho o ́ \zeta$, era, pues, el enviado de la polis al oráculo o a las fiestas. 
- $\Theta \varepsilon \omega p ı$ ќéran los dineros dados por el Estado a los atenienses pobres para que asistieran a los espectáculos y pagasen su asiento en los mismos.

- $\Theta \varepsilon \omega p r \zeta$ era la nave sagrada que transportaba a los peregrinos.

- $\quad \Theta \varepsilon \omega ́ p \eta \mu \alpha$ es el resultado de lo que se ve u ofrece a la vista. Tiene el sufijo -ma, ya analizado.

- Oecopió, por tanto, es visión ( ya sea en la aduana o la propia del veedor encargado de velar, cuidar) pero alude al mismo tiempo a una misión sagrada y a una fiesta, certamen o expedición de carácter religioso. El término teoría, para algunos autores (entre ellos, el filósofo Federico (amino) ${ }^{2}$, encierra el término theos,

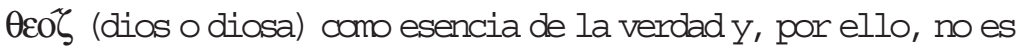
"especulación", palabra latina derivada de speculari (mirar) pero cuyo significado se asemeja al de "conjetura" (opinión sobre algo sobre la base de indicios). Teoría es un mirar comprometido de la verdad íntimamente ligado a la praxis.

- El verbo \&pouoa, que significa filosóficamente preguntar, nace del asombro $(\theta \alpha v \mu \alpha \xi \varepsilon v v)$, y coloca al hombre frente a sus grandes enigmas. Comprende esta palabra el eros, $\varepsilon \rho o \zeta$ como amor, pues sólo en el amor es pasible llegar a la sabiduría. Ia reflexión sobre la pregunta, $\varepsilon \rho o \tau \eta \sigma \zeta$, se convierte en Aristóteles en un estudio taxonómico cuyo centro es la noción misma de problema ${ }^{3}$. Posteriormente Heidegger se interesará por la pregunta e incluirá como contenido en ella lo que aparece con mayor claridad en los términos derivados del latín "preguntar" e "interrogar" (cf. parte

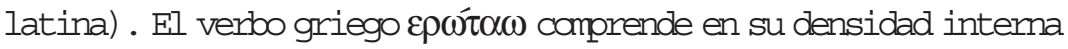
el significado de pedir, rogar, suplicar y querer. Ambos significados se encuentran con claridad en diversos pasajes del griego neotestamentario, principalmente en los escritos del evangelista Jran.

- Ia raíz del verbo ójo (conducir, llevar) aparece en castellano en palabras tales como pedagogía ( $\pi \alpha 1 \zeta+\alpha \gamma \omega=$ conducir al niño) y demagogo ( $\delta \eta \mu \mathrm{o} \zeta+\alpha \gamma \omega=$ conducir al pueblo) 
- Una raíz, parecida en su forma pero de diferente significado, es la del verbo oyopevá (hablar en la asamblea) , y que se conserva en castellano -en los sustantivos ágora y agorero-con ese valor inconporado (significan respectivamente "lugar de reunión" y "el que habla" en la misma) .

- La raíz griega $\beta \varepsilon \lambda-/ \beta 0 \lambda-/ \beta o \boldsymbol{~ - ~ ( = ~ l a n z a r , ~ a r r o j a r ) ~ a p a r e c e ~}$ en palabras como bala, diablo, $(\delta \mathrm{t} \alpha+\beta \alpha \lambda \lambda \omega)$, parábola $(\pi \alpha p \alpha$ $+\beta$ o $\lambda \eta$ ), problema (prefijo $\pi \rho 0+\beta \varepsilon \lambda \circ \zeta=$ proyectil + sufijo $\mu \alpha)$ = lo que se ha arrojado o lanzado delante.

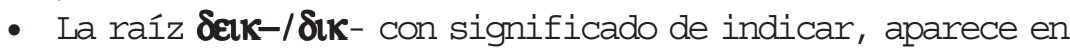

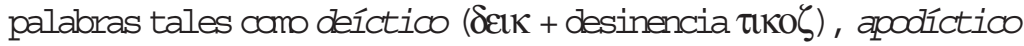
$(\alpha \pi \mathrm{o}+\delta \varepsilon 1 \kappa \tau \kappa \kappa \zeta)$, paradigma $(\pi \alpha \rho \alpha+\delta \varepsilon \iota \kappa+\mu \alpha)$.

- La raíz סok- (= opinar, creer) ha producido la palabra castellana

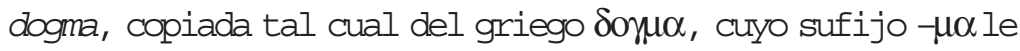
confiere el valor de "lo resultante"; o sea, la opinión que -después de una criba de opiniones- deviene en creencia. También

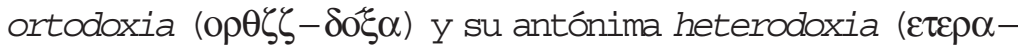
$\delta o ́ \xi \alpha)$, opinión recta y contraria, respectivamente. Paradoja $(\pi \alpha \rho \alpha-\delta o \xi \alpha)$ es la opinión que se halla al margen de lo esperado, de lo creíble.

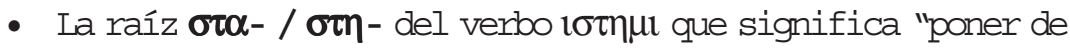
pie", "estar parado", "estar firme", aparece en palabras tales como

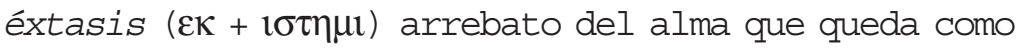
levantada fuera del cuerpo; sistema ( $\sigma v v+1 \sigma \tau \eta \mu \mathrm{l}=$ colocar conjuntamente) ; y otras, como metástasis, próstata, estático, hipostático, todas ellas formadas por los prefijos ya mencionados y el verbo en cuestión. Se trata de una raíz indeuropea, que aparece también en sánscrito. Un ejemplo de ello es la palabra "esvástica" aplicada a la cruz, utilizada en la cultura hindú, y retomada luego como símbolo del grupo nazi. El vocablo

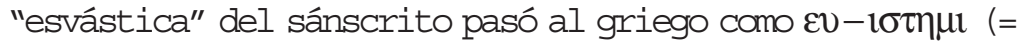
bienestar) . La cruz aludida expresa gráficamente "estabilidad" y, por ende, "bienestar".

La misma raíz tiene su equivalente en latín en la raíz "st" con el mismo valor. 
- La raíz del verbo ouotóvouoa (= percibir), ha dado lugar al vocablo esteta. Es curioso notar que la única palabra castellana derivada de esta raíz ha sido usada para señalar a la persona sensible a estímulos de orden artístico, no físico. Para referirse a éste, se han inventado palabras que denotan la condición más bien de insensibilidad o sensibilidad no común, como anestesia ohiperestestia.

- En el verbo $\boldsymbol{k} \lambda \mathbf{i} \boldsymbol{\omega} \omega$ (= acostar) se esconde una raíz que se manifiesta en una serie de palabras como in-clinarse, pro-clive, de-clinar. Llamamos en-clítica (ni in-clítica ni en-clínica...) a la palabra que se apoya, prosódicamente, en otra que la precede. Más directa es la derivación al vocablo clínica (el lugar donde uno se acuesta). Clima tiene que ver también con la inclinación, la del cielo, de la que dependen las temperaturas; asimismo, clímax, palabra que indica una gradación.

- Tomando como base la raíz del verbo $\boldsymbol{k p i ́ v \omega ~ ( = ~ s e p a r a r , ~}$ discernir), se han ido formando palabras que siempre se relacionan con su reserva original de sentido. Así el crítico es un buen separador (de aspectos buenos, malos, notables, dignos en todo caso de tener en cuenta...) , como lo es también el discreto o discriminador. Como sucede tantas veces, hay derivados castellanos que tienen su fuente más próxima en el latín; es el caso de secreto (aquello que se pone aparte, escondido) . Especialmente interesante es la formación de hipócrita, la persona que simula ser quien no es en realidad. Su carga peyorativa cayó sobre la palabra siglos más tarde, ya que los griegos significaron con ella simplemente a los actores de teatro '(

- Lo interesante de la raíz $\boldsymbol{\theta \eta}$ - / $\boldsymbol{\theta \varepsilon}-$, inserta en el fundamental verbo $\pi \hat{\theta} \eta \mu \mathrm{u}=$ colocar, es notar que los derivados castellanos han ido acompañando, en su mayor parte, los mismos prefijos griegas. De esta forma, tenemos las palabras tesis $(\theta \varepsilon \sigma ́ l \zeta)$, prótesis, sín-tesis, antí-tesis; ana-tema (calcada del original ana-qh + sufijo -ma) ; y pinaco-teca $(\pi \mathrm{v} \alpha \xi+\theta \eta \kappa \eta)$.

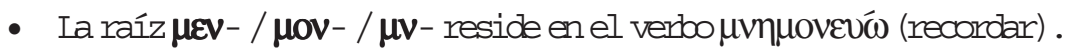
Es cierto que la palabra "memoria" nos ha llegado a través del latín; pero, en nuestra lengua, tenemos términos que han 
conservado tenazmente la raíz griega, a pesar de que ello ha obligado, para pronunciarlos, a un esfuerzo inusual entre nosotros. Tales son mnemotecnia o mnemotécnica. Encontramos también en uso amnesia y anamesia, a-mesia y a-mistía (olvido político).

- Son pocas las palabras castellanas derivadas de $\phi \eta \mu{ }^{\prime}$ (= decir), verbo del que cabría esperar mayor fortuna, ya que expresa una acción tan primordial en el ser humano. Recogemos eufemismo $(\varepsilon v+\phi \eta \mu \mathrm{u})$, blasfemia, pro-feta (no, por cierto, el que dice las cosas "antes de" que sucedan, sino el que habla "en lugar de" otro) y a-fasia. El término "infante", que llega al castellano a través del latín, contiene la raíz de este verbo griego, precedido del prefijo latino in- de valor negativo: "infante" es, pues, semánticamente "el que no habla".

- Suerte similar a la que tuvo la precedente le tocó también a la

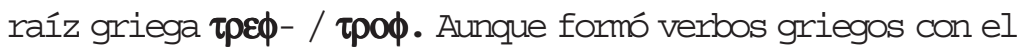
significado básico de "comer", éstos no fueron tan usados como para que prosperara la formación de derivados en lenguas tributarias de la griega. En realidad, sólo un derivado castellano intentó, y sin éxito, abrirse paso: el adjetivo trófico (es decir, alimenticio) . Nos referimos a derivados directos y positivos. Sí ha sobrevivido desde el s. XVI atrofia, al que sucedió más tarde distrofia e hipertrofia. Existen compuestos, como orfano-trofio (donde se alimentan los huérfanos) y heterótrofo (ser que se alimenta de otros seres vivos) .

- La raíz $\pi \lambda \varepsilon$ - / $\pi \lambda \eta$ - (ver el verbo correspondiente $\pi \lambda \eta \theta \omega=$ estar lleno) , indicativa de abundancia, pasó al latín, y es fácilmente reconocible en bastantes vocablos castellanos: pleno con su aumentativo repleto, pletórico, plenitud, plenario, plecnasmo (figura literaria que indica una exageración expresiva). Para los siglos XV y XVI sobrevino la conversión del sonido pl al 11 produciéndose Ilen, rellerar.

- La raíz $\phi \rho$ - / $\phi \rho \varepsilon v$ - encierra el sentido de pensar. Existe el sustantivo griego frhn cuyo significado es "mente". Se hizo

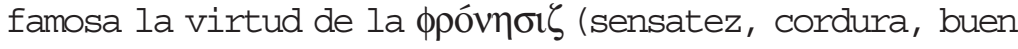
criterio...) en la cultura griega antigua. Curiosamente los 
derivados castellanos han seguido una senda más bien peyorativa: frenesí, frenopatía... Por más que, en nombre de razones semiológicas, haya quienes sientan la tentación de buscar etimologías comunes a frenético y desenfrenado, este último vocablo tiene una procedencia latina del toob ajena a la raíz griega que ahora nos ocupa.

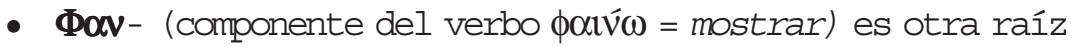
pródiga en la generación de términos de interés en la lengua castellana. Antes de generarse los términos fantasía y fantástico, se popularizó la voz fantasma (aunque su derivado fantasmagórico es muy posterior) . Fenómeno proviene también de la misma raíz, lo mismo que diá-fanoy epi-fanía.

\section{Notas}

* En este artículo están recogidos algumos fragmentos de la investigación "Un estudio sobre etimologías greco-latinas y su repercusión en vocablos de la lengua castellana", que presenté al Instituto de Investigaciones Humanísticas, de la UNMSM, en noviembre de 2001.

1 Se trata de la hipótesis de que las palabras castellanas derivadas del latín y/o griego conllevan desde su origen una reserva de sentido (densidad semántica, sugiero llamarla) que está presente en su interior, y que en su transitar a lo largo del tiempo va explicitando unos u otros aspectos sustanciales de su sentido, de acuerdo a la demanda o necesidades de la comunidad hablante.

2 El filósofo y profesor de la Pontificia Universidad Católica del Perú, Dr. Federico Camino, tuvo la gentileza de proporcionarme unos apuntes manuscritos de trabajo en los cuales me he inspirado para hablar acerca de los términos relacionados con "teoría".

3 Federico Camino "Reflexiones sobre la pregunta". Separata de la Pontificia Universidad católica del Perú.

\section{Referencia bibliográfica}

ISIDORO DE SEVIIIA (1982) : Etimologías. Texto latino y traducción al castellano de José Oroz Reta y Manuel Marcos Casquero. Editorial BAC. Madrid. 